Artigo original

Hegemonia - Revista Eletrônica do Programa de Mestrado em Direitos Humanos, Cidadania e

Violência/Ciência Política do Centro Universitário Unieuro

ISSN: $1809-1261$

UNIEURO, Brasília, número 25 (Especial), 2018, pp. 219-231.

Recebido em: 23/3/2018

Avaliado em: 17/4/2018

Aprovado em: 29/5/2018

\title{
ANÁLISE DA ATUAÇÃO DO TERCEIRO SETOR NO SISTEMA ÚNICO DE SAÚDE - O CASO DO DISTRITO FEDERAL
}

Lucas Cunha Azevedo e Carla Pintas Marques²

Resumo: O objetivo desse estudo é comparar aspectos gerenciais de hospitais localizados no Distrito Federal (DF) e geridos por instituições do terceiro setor, e, a partir dessa comparação, estabelecer relações com o Instituto Hospital de Base do Distrito Federal (IHBDF), que consiste em uma instituição do terceiro setor que assumiu recentemente a gestão da maior unidade de saúde do DF. Os hospitais analisados foram o Hospital da Criança de Brasília (HCB) e as unidades da Rede Sarah de Hospitais de Reabilitação localizadas no DF. Foram extraídos dos contratos de gestão celebrados com o poder público e dos relatórios anuais de gestão elaborados pelas instituições gestoras, dados referentes aos repasses financeiros e ao cumprimento de metas quanti e quali. Foram identificados importantes atrasos nos repasses financeiros do HCB durante o período analisado, bem como dotações orçamentárias significativas oriundas de emendas parlamentares na Rede Sarah. Em relação ao cumprimento de metas, foi identificado um cenário totalmente desfavorável para o cumprimento no HCB, e, em contrapartida, um cenário bastante favorável na Rede Sarah. Relacionando os dados encontrados com o IHBDF, foram encontrados alguns fatores presentes tanto no HCB quanto na Rede Sarah que dizem muito a respeito das possibilidades de sucesso do modelo de gestão recentemente implementado.

Palavras-chave: terceiro setor; contrato de gestão; modelo de gestão; Sistema Único de Saúde.

Abstract: The objective of this study is to compare management aspects of hospitals locateds in Federal District (DF) and managed by institutions of third sector, and, from this comparison, establish relations with the Bill No. 1,486/2017 which create the Institute Base Hospital of the Federal District (IHBDF). The hospitals analyzed were the Children's Hospital of Brasilia (HCB) and the the Sarah Network units of Rehabilitation Hospitals located in DF. Data on financial onlendings and the fulfillment of quantitative and qualitative target were extracteds from the management contracts entered into with the public

\footnotetext{
${ }^{1}$ Bacharel em Saúde Coletiva.

2 Doutoranda em Saúde Coletiva pela Universidade de Brasília.
} 
Artigo original

Hegemonia - Revista Eletrônica do Programa de Mestrado em Direitos Humanos, Cidadania e

Violência/Ciência Política do Centro Universitário Unieuro

ISSN: 1809-1261

UNIEURO, Brasília, número 25 (Especial), 2018, pp. 219-231.

authority and the anual management articles drawn up by management institutions. Significant delays in HCB`s onlendings were identified during the review period, as well as significants budgets allocations from parliamentary amendments in the Sarah Network. In relation to the meeting goals, it was identified a totally unfavorable scenario for fulfillment at $\mathrm{HCB}$, and, on the other hand, a very favorable scenario in the Sarah Network. Relating the data found with the IHBDF, it was found some factors present both at HCB and in the Sarah Network, which say a lot about the possibilities of success of the management model proposed by the Bill No. 1,486/2017.

Keywords: Third sector; management contracts; management model.

Introdução

Na década de 90, após anos de discussão acerca da administração pública brasileira, iniciou-se uma reforma que teve como base o Plano Diretor da Reforma do Aparelho do Estado (PDRAE) de 1995. Com o objetivo de trocar a chamada administração pública burocrática, que consistia em um modelo engessado de administração e que tornava os processos de tomada de decisão ineficientes, por um modelo chamado de administração pública gerencial, que consiste em uma modalidade cuja principal característica é a maleabilidade dos seus processos, o PDRAE visava tornar possíveis novas formas de gestão e uma gerência focada no atendimento a sociedade, com isso, foi possível a criação de novos modelos de gestão constituídos por entidades do terceiro setor (1).

Abrangendo todas as modalidades de gestão criadas a partir do PDRAE, o chamado terceiro setor é constituído por instituições sem fins lucrativos com as quais o poder público estabelece parcerias para a prestação de serviços públicos do setor de atividades não exclusivas, setor que abrange os serviços prestados pelo Estado, mas que não são exclusivos a ele, como os hospitais.

Após as mudanças ocorridas na década de 1990, novos modelos de gestão continuam a surgir na tentativa de suprir as necessidades que os modelos atuais não conseguem (2). Um exemplo disso é o IHBDF, que consiste em um Serviço Social Autônomo, com características bem específicas e que foi criado com o objetivo de assumir a gestão do Hospital de Base do Distrito Federal (HBDF). Por se tratar de um modelo de gestão recentemente implementado, uma análise do projeto se faz de grande importância para que possa gerar base teórica para as decisões que serão tomadas na gestão da unidade hospitalar em questão, e para que oriente a população acerca das possibilidades que o projeto visa. 
Artigo original

Hegemonia - Revista Eletrônica do Programa de Mestrado em Direitos Humanos, Cidadania e

Violência/Ciência Política do Centro Universitário Unieuro

ISSN: 1809-1261

UNIEURO, Brasília, número 25 (Especial), 2018, pp. 219-231.

Tendo o DF como plano de fundo da análise realizada, o presente trabalho busca estabelecer relações entre os aspectos gerenciais identificados nos hospitais do DF que são geridos por instituições do terceiro setor e o IHBDF. Os hospitais utilizados como referência para a análise são o HCB e os hospitais da Rede Sarah localizados em Brasília, que são até o momento, as únicas unidades cuja gestão é feita por instituições do terceiro setor no DF.

Objetivos

Comparar os modelos de gestão utilizados no HCB e na Rede Sarah, e relacionar os aspectos gerenciais encontrados com o modelo proposto no IHBDF.

Revisão de literatura

A partir da Emenda Constitucional no 19/98, o modelo de administração pública burocrática foi substituído pelo modelo de administração pública gerencial, validando algumas propostas apresentadas no PDRAE. Com isso, atividades de interesse social e que antes eram exercidas pelo Estado, passaram a ser passíveis de serem exercidas também por pessoas jurídicas de direito privado sem fins lucrativos por meio de contratos de gestão celebrados com o Poder Público. Esse cenário de parcerias entre o governo e as instituições de direito privado para a prestação de serviços de interesse social, compõe o chamado terceiro setor (3).

Com todas as mudanças ocorridas na década de 90, o terceiro setor passou a se caracterizar como uma grande promessa para a administração pública, mas, que ao mesmo tempo, tinha como principal desafio provar a sua capacidade de gerenciamento questionada por muitos atores sociais ao longo do tempo, provavelmente, devido ao grande número de instituições, que das mais diversas áreas de atuação e de origem, se qualificaram como aptas a estabelecer parcerias com o governo e dessa forma atuar no terceiro setor (4).

Em relação a personalidade jurídica, todas as instituições do terceiro setor se classificam como fundações ou associações, independentemente do termo que utilizam em suas razões sociais. 
Artigo original

Hegemonia - Revista Eletrônica do Programa de Mestrado em Direitos Humanos, Cidadania e

Violência/Ciência Política do Centro Universitário Unieuro

ISSN: 1809-1261

UNIEURO, Brasília, número 25 (Especial), 2018, pp. 219-231.

No momento em que se cria uma entidade sem fins lucrativos, a escolha da personalidade jurídica mais adequada - fundação ou associação - irá depender de quantas pessoas irão colaborar com o projeto, o patrimônio com o qual será constituída a entidade, bem como os propósitos e as práticas gerenciais pretendidas (5).

As instituições do terceiro setor, que são sempre classificadas como associações ou fundações, podem pleitear determinadas qualificações ou títulos junto ao Estado. Tais títulos e qualificações são facultativos, porém, por meios destes a instituição poderá obter vantagens fiscais, diferenciar-se de outras entidades sendo inseridas em um regime jurídico específico, facilitar a obtenção de captação de investimentos privados e financiamentos, entre outros benefícios.

Os títulos e qualificações podem ser pleiteados em âmbito municipal, estadual e federal. Na esfera federal, as instituições podem obter os seguintes: Título de Utilidade Pública Federal, Certificado de Entidade Beneficente de Assistência Social, Qualificação como Organização da Sociedade Civil de Interesse Público e Qualificação como Organização Social.

Métodos

O presente estudo consiste em uma análise documental acerca dos modelos de gestão utilizados em hospitais públicos do DF geridos por meio de parcerias com instituições do terceiro setor. Foram comparados os modelos de gestão utilizados no HCB e nas unidades da Rede Sarah de Hospitais de Reabilitação localizadas em Brasília.

O HCB é gerido por meio de um contrato de gestão celebrado entre a Secretaria de Saúde do Distrito Federal (SES/DF) e o Instituto do Câncer Infantil e Pediatria Especializada (Icipe), já a Rede Sarah, é gerida por meio de um contrato celebrado entre a União Federal e a Associação das Pioneiras Sociais (APS).

A partir da apreciação dos contratos de gestão celebrados, foram extraídas as metas quanti e qualitativas estipuladas, e os repasses financeiros que deveriam ocorrer por parte do Estado. Posteriormente, foram apreciados os relatórios anuais de gestão de cada uma das instituições com a finalidade de verificar o cumprimento das metas por parte das contratadas, e se os repasses financeiros ocorreram da maneira prevista por parte das contratantes. Os contratos de gestão analisados foram o de vigência 2011-2014 no caso do HCB, e o de vigência 2011-2015 no caso da Rede Sarah. 
Artigo original

Hegemonia - Revista Eletrônica do Programa de Mestrado em Direitos Humanos, Cidadania e Violência/Ciência Política do Centro Universitário Unieuro

ISSN: 1809-1261

UNIEURO, Brasília, número 25 (Especial), 2018, pp. 219-231.

No ano de 2014, os únicos meses contemplados pelo contrato de gestão analisado, celebrado entre a SES/DF e o Icipe, para gestão do HCB, correspondem á janeiro e fevereiro. Os dados desses meses não são apresentados em nenhum relatório de gestão, uma vez que, o relatório de 2014 já se inicia com os dados de março, mês em que se inicia a vigência do segundo contrato celebrado. Sendo assim, o ano de 2014 foi excluído da análise de metas quanti e qualitativas do HCB.

Após a comparação dos dados, as constatações observadas foram relacionadas com o modelo de gestão proposto pelo IHBDF.

A abrangência do estudo é a nível estadual, uma vez que analisa instituições do DF.

Resultados

- Hospital da Criança de Brasília: repasses financeiros

Os dados observados referentes aos repasses financeiros da SES/DF para o Icipe durante o período analisado, permitiram constatar que todos os depósitos ocorreram com atrasos, com alguns chegando a 146 dias. 
Artigo original

Hegemonia - Revista Eletrônica do Programa de Mestrado em Direitos Humanos, Cidadania e Violência/Ciência Política do Centro Universitário Unieuro

ISSN: 1809-1261

UNIEURO, Brasília, número 25 (Especial), 2018, pp. 219-231.

Quadro 1 - Quadro síntese de repasses financeiros da SES/DF para o Icipe em relação às datas previstas/datas de depósito do ano de 2011 a 2014.

\begin{tabular}{|c|c|c|c|}
\hline REPASSE & ATRASO & REPASSE & ATRASO \\
\hline Julho de 2011 & 18 dias & Janeiro de 2013 & 83 dias \\
\hline Agosto de 2011 & 41 dias & Fevereiro de 2013 & 52 dias \\
\hline Setembro de 2011 & 71 dias & Março de 2013 & 24 dias \\
\hline Outubro de 2011 & 86 dias & Abril de 2013 & 132 dias \\
\hline Novembro de 2011 & 115 dias & Maio de 2013 & 102 dias \\
\hline Dezembro de 2011 & 85 dias & Junho de 2013 & 71 dias \\
\hline Janeiro de 2012 & 78 dias & Julho de 2013 & 119 dias \\
\hline Fevereiro de 2012 & 88 dias & Agosto de 2013 & 88 dias \\
\hline Março de 2012 & 59 dias & Setembro de 2013 & 57 dias \\
\hline Abril de 2012 & 121 dias & Outubro de 2013 & 27 dias \\
\hline Maio de 2012 & 91 dias & Novembro de 2013 & - \\
\hline Junho de 2012 & 60 dias & Dezembro de 2013 & - \\
\hline Julho de 2012 & 146 dias & Janeiro de 2014 & - \\
\hline Agosto de 2012 & 114 dias & Fevereiro de 2014 & - \\
\hline Setembro de 2012 & 83 dias & \multirow{2}{*}{\multicolumn{2}{|c|}{ MAIOR ATRASO: 146 dias. }} \\
\hline Outubro de 2012 & 55 dias & & \\
\hline Novembro de 2012 & 21 dias & \multirow{2}{*}{\multicolumn{2}{|c|}{$\begin{array}{l}\text { MENOR ATRASO: } 18 \text { dias. } \\
\text { MÉDIA DE ATRASO: } 79 \text { dias. }\end{array}$}} \\
\hline Dezembro de 2012 & 114 dias & & \\
\hline
\end{tabular}

Fonte: Relatórios anuais de gestão. Elaborado pelo autor.

Do mês de novembro de 2013 ao mês de fevereiro de 2014, não foi possível calcular os atrasos nos repasses devido à falta de informações nos relatórios analisados, entretanto, foi possível observar que todos os repasses desse período ocorreram com mais de 30 dias de vencimento.

- Hospital da Criança de Brasília: metas quantitativas 
Artigo original

Hegemonia - Revista Eletrônica do Programa de Mestrado em Direitos Humanos, Cidadania e Violência/Ciência Política do Centro Universitário Unieuro

ISSN: 1809-1261

UNIEURO, Brasília, número 25 (Especial), 2018, pp. 219-231.

As metas quantitativas analisadas são referentes ao número de consultas médicas, número de consultas de assistência complementar essencial, número de procedimentos assistenciais de alta complexidade, números de leitos ocupados por dia e número de procedimentos prestados pelo Serviço de Apoio Diagnóstico Terapêutico (SADT).

Gráfico 1 - Cumprimento de metas quantitativas no HCB no período de 2011 a 2013.

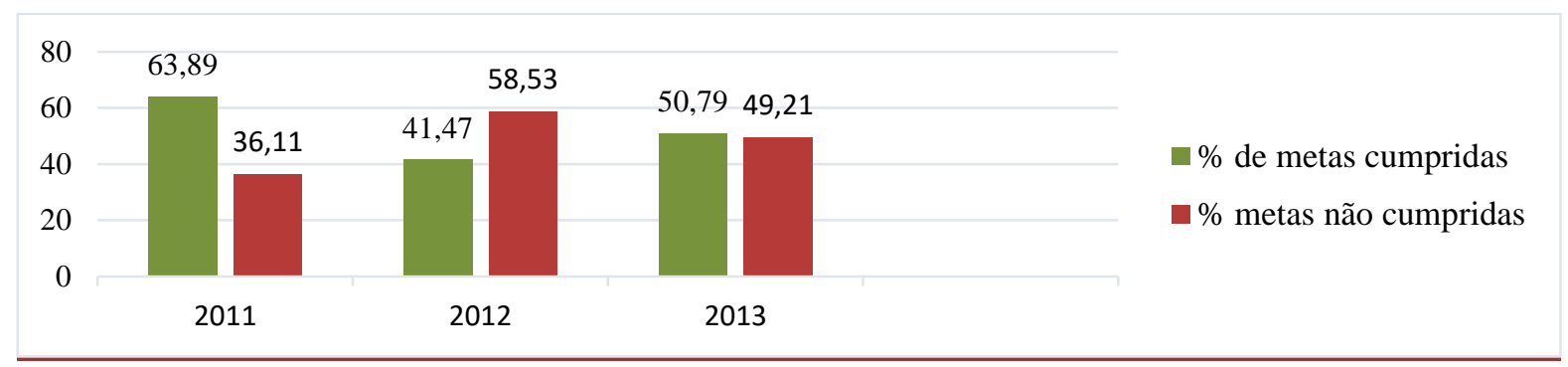

Fonte: Elaborado pelo autor.

- Hospital da Criança de Brasília: metas qualitativas

As metas qualitativas analisadas consistem em meta de satisfação do cliente externo, meta de satisfação do cliente interno e meta do serviço de atenção ao usuário/ouvidoria.

Gráfico 2 - Cumprimento de metas qualitativas no HCB no período de 2011 a 2013.

\begin{tabular}{|c|c|c|c|c|}
\hline \multicolumn{5}{|l|}{150} \\
\hline & 100 & 100 & 100 & \multirow{3}{*}{$\%$ de metas cumpridas } \\
\hline 50 & & & & \\
\hline & 2011 & 2012 & 2013 & \\
\hline
\end{tabular}

Fonte: Elaborado pelo autor. 
Artigo original

Hegemonia - Revista Eletrônica do Programa de Mestrado em Direitos Humanos, Cidadania e Violência/Ciência Política do Centro Universitário Unieuro

ISSN: 1809-1261

UNIEURO, Brasília, número 25 (Especial), 2018, pp. 219-231.

- Rede Sarah de Hospitais de Reabilitação: repasses financeiros

Ao contrário do HCB, hospital analisado anteriormente, a Rede Sarah não apresenta em seus relatórios anuais de gestão as datas em que ocorreram os depósitos referentes aos repasses financeiros dos anos analisados, porém, é de conhecimento geral que atrasos nos repasses da União Federal para a APS não são um problema para a gestão da instituição por não ser algo recorrente. Por não ser possível analisar os repasses financeiros com relação as datas previstas e as datas de depósito, a análise da Rede Sarah focou nas execuções orçamentárias dos anos de 2011 a 2015.

Quadro 2 - Quadro síntese de repasses financeiros da União Federal para a APS entre 2011 e 2015.

\begin{tabular}{|c|c|c|c|c|c|}
\hline \multicolumn{6}{|c|}{ REPASSES (em milhões de R\$) } \\
\hline & 2011 & 2012 & 2013 & 2014 & 2015 \\
\hline $\begin{array}{l}\text { Valor solicitado no } \\
\text { orçamento-programa }\end{array}$ & 663 & $\begin{array}{l}\text { Inf. não } \\
\text { disponível }\end{array}$ & 784 & $\begin{array}{l}\text { Inf. não } \\
\text { disponível }\end{array}$ & $\begin{array}{l}\text { Inf. não } \\
\text { disponível }\end{array}$ \\
\hline $\begin{array}{l}\text { Valor repassado pela União } \\
\text { Federal }\end{array}$ & 628 & \multirow{2}{*}{751} & 743 & 750 & 890 \\
\hline $\begin{array}{l}\text { Valor disponibilizado por } \\
\text { emendas parlamentares }\end{array}$ & 65 & & 70 & 33 & - \\
\hline Outras verbas & 25 & 22 & 30 & $\begin{array}{l}\text { Inf. não } \\
\text { disponível }\end{array}$ & $\begin{array}{l}\text { Inf. não } \\
\text { disponível }\end{array}$ \\
\hline $\begin{array}{c}\text { Total (repasse }+ \text { emendas }+ \\
\text { outras verbas) }\end{array}$ & 693 & 751 & 843 & 783 & 890 \\
\hline Deduções & 17 & 35 & - & - & - \\
\hline Repasses atrasados & Não & Não & Sim & Sim & Não \\
\hline $\begin{array}{l}\text { Valores retroativos } \\
\text { referentes a atrasos }\end{array}$ & - & - & - & $62 *$ & $20 * *$ \\
\hline Valor final para o exercício & 701 & 738 & 781 & $845^{* * *}$ & $910^{* * *}$ \\
\hline EXEC & $\tilde{A} \mathrm{O} O$ & MENTÁRI & milhe & $\mathrm{R} \$)$ & \\
\hline Despesas com pessoal & 517 & 554 & 608 & 625 & 724 \\
\hline Despesas com custeio, & 135 & 107 & 115 & 144 & 158 \\
\hline
\end{tabular}


Artigo original

Hegemonia - Revista Eletrônica do Programa de Mestrado em Direitos Humanos, Cidadania e Violência/Ciência Política do Centro Universitário Unieuro

ISSN: 1809-1261

UNIEURO, Brasília, número 25 (Especial), 2018, pp. 219-231.

\begin{tabular}{l}
$\begin{array}{l}\text { tributos, equipamentos e } \\
\text { reformas }\end{array}$ \\
\hline Total
\end{tabular}

Fonte: Elaborado pelo autor.

- Rede Sarah de Hospitais de Reabilitação: metas quantitativas

As metas quantitativas apreciadas foram as de número de consultas médicas, número de atendimentos de assistência complementar essencial, procedimentos do SADT, internações e cirurgias.

Gráfico 3 - Cumprimento de metas quantitativas na Rede Sarah no período de 2011 a 2015.

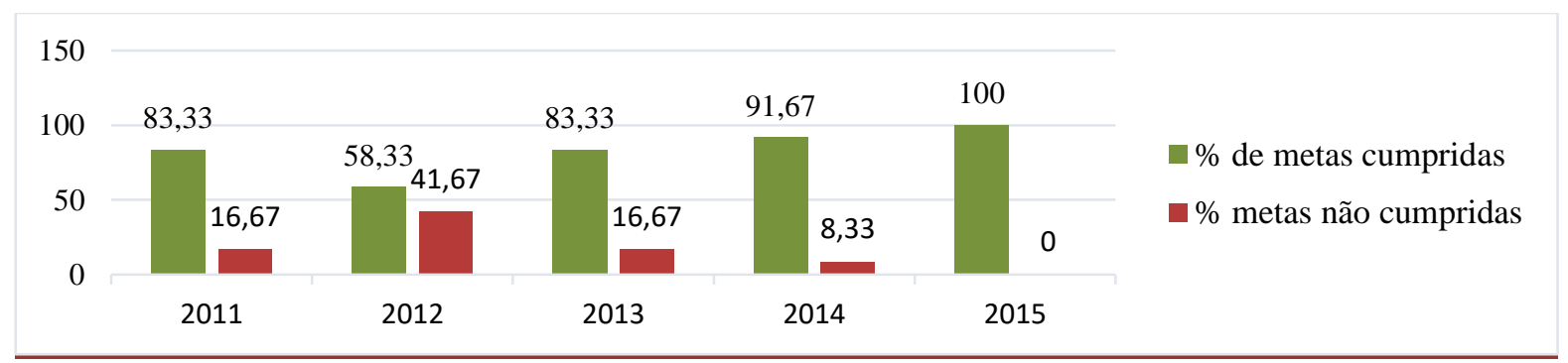

Fonte: Elaborado pelo autor.

- Rede Sarah de Hospitais de Reabilitação: metas qualitativas

As metas qualitativas analisadas foram as de taxa de infecção hospitalar, taxa de supuração em incisão cirúrgica limpa, taxa de ocupação hospitalar e satisfação do usuário. 
Artigo original

Hegemonia - Revista Eletrônica do Programa de Mestrado em Direitos Humanos, Cidadania e Violência/Ciência Política do Centro Universitário Unieuro

ISSN: 1809-1261

UNIEURO, Brasília, número 25 (Especial), 2018, pp. 219-231.

Gráfico 3 - Cumprimento de metas qualitativas na Rede Sarah no período de 2011 a 2015.

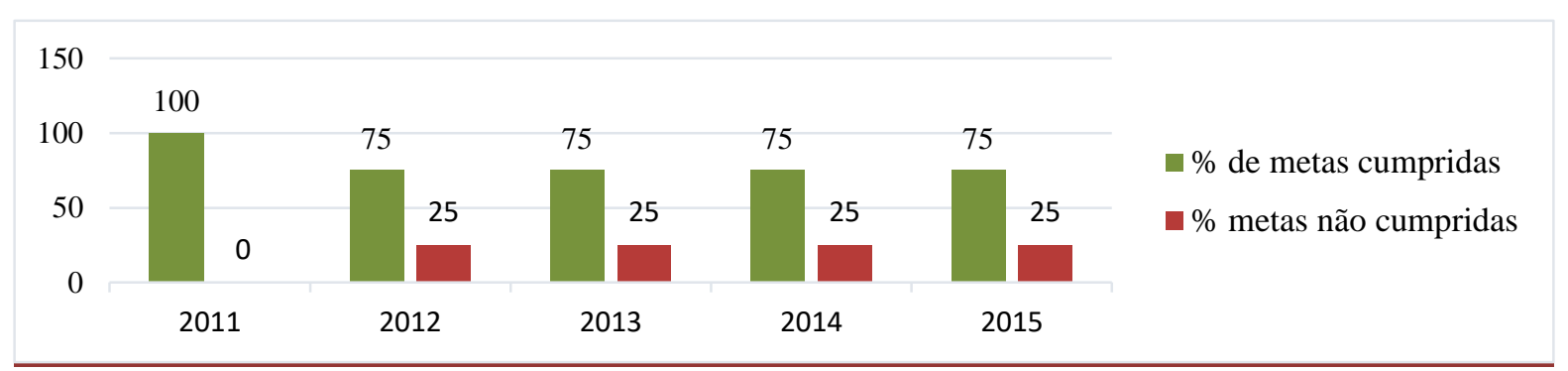

Fonte: Elaborado pelo autor.

Discussão

A análise se iniciou com a apreciação dos dados disponíveis acerca dos repasses financeiros do HCB e da Rede Sarah. Em relação a essa primeira análise, o que se observou é que a Rede Sarah por se tratar de uma instituição cujo contrato foi celebrado com a União, os repasses ocorrem de maneira bem mais efetiva e dentro dos prazos do que os repasses recebidos pelo HCB, cuja origem é a SES/DF. A APS, instituição que gere a Rede Sarah, durante o período analisado só manifestou em seus relatórios anuais atrasos nos repasses financeiros referentes aos anos de 2013 e 2014, enquanto o Icipe manifestou atrasos nos repasses financeiros de todos os meses dos anos analisados, com alguns chegando a serem depositados 146 dias após a data prevista.

A Rede Sarah se diferencia do HCB em relação aos repasses financeiros também por conseguir se beneficiar de emendas parlamentares, que contribuem no orçamento de forma bastante significativa. No ano de 2013, R\$ 69,1 milhões foram disponibilizados por meio de emendas, enquanto o HCB tem seus repasses sendo feitos exclusivamente nos valores pré-acordados no contrato de gestão com a SES/DF.

Comparando o cumprimento das metas quantitativas do HCB e das unidades da Rede Sarah localizadas no DF, é possível observar que a quantidade de metas não cumpridas durante o período analisado é muito maior no HCB, esse fato pode ter relação com diversos aspectos do contexto em que a instituição se encontra, mas, dois aspectos em especial se sobressaem, são eles os recorrentes atrasos nos repasses financeiros por parte da contratante SES/DF, e o pouco tempo de existência do hospital durante a vigência do contrato analisado, que pode dificultar uma estabilização dos processos de trabalho e de atendimento, impossibilitando o cumprimento das metas estabelecidas. 
Artigo original

Hegemonia - Revista Eletrônica do Programa de Mestrado em Direitos Humanos, Cidadania e

Violência/Ciência Política do Centro Universitário Unieuro

ISSN: 1809-1261

UNIEURO, Brasília, número 25 (Especial), 2018, pp. 219-231.

A Rede Sarah por se tratar de uma instituição com muitos anos de existência, conta com um maior conhecimento da demanda dos usuários que fazem uso de seus serviços anualmente, fazendo com que a previsão dos números de produção seja mais precisa e possibilite uma determinação de metas a serem cumpridas mais realista. Essa elaboração de metas com base nos números de produção alcançados anteriormente não foi possível na elaboração das metas do HCB, já que não existia um histórico de atendimento exclusivo de pediatria especializada para ser utilizado durante o processo de elaboração. Outra questão relevante em relação às metas, e que diferencia a Rede Sarah do HCB, é o fato da Rede Sarah elaborar anualmente as suas metas por meio do plano de trabalho anual, já o HCB tem suas metas estabelecidas pelo próprio contrato de gestão, fazendo com que sejam fixas durante toda a vigência.

A análise do presente trabalho relacionou os repasses financeiros com o cumprimento de metas quanti, e tornou possível observar que as metas qualitativas dizem muito a respeito da eficiência da gestão das unidades analisadas, pois, valores quanti como de número de consultas médicas, podem ter seu cumprimento inviabilizado pela falta de verba ou por uma meta que foi estabelecida de maneira equivocada, porém, as metas qualitativas mostram o esforço da gestão de cada instituição em prestar um serviço de qualidade para o usuário, independentemente dos percalços originados pela falta de recursos e outros problemas que dificultam o trabalho gerencial. Um exemplo disso é apresentado por meio das metas de satisfação do usuário das duas instituições analisadas, onde foram observadas taxas acima de 90\% mesmo com atrasos nos repasses financeiros tão recorrentes como no caso do HCB.

Conclusão

Após analisar todos os dados coletados referentes a repasses financeiros, metas quantitativas e metas qualitativas do HCB e da Rede Sarah, foi possível estabelecer uma relação com o IHBDF.

Entre as duas instituições analisadas, o IHBDF se assemelha mais com o HCB devido as suas proporções e ao fato do contrato ser celebrado com a mesma contratante, no caso a SES/DF. Porém, na personalidade jurídica, o IHBDF se assemelha com a Rede Sarah que é gerida por SSA, mesma forma jurídica do instituto.

O caso dos repasses sempre atrasados no HCB levanta a suspeita de que ocorreria de forma igual no IHBDF pelo fato da contratante ser a mesma, porém com um agravante, no HCB a demanda é programada, ou seja, os usuários são atendidos de forma agendada e regulados pelo Sistema Nacional de 
Artigo original

Hegemonia - Revista Eletrônica do Programa de Mestrado em Direitos Humanos, Cidadania e

Violência/Ciência Política do Centro Universitário Unieuro

ISSN: 1809-1261

UNIEURO, Brasília, número 25 (Especial), 2018, pp. 219-231.

Regulação (SISREG), o que torna possível um melhor planejamento e a elaboração de estratégias para atendê-los mesmo com repasses atrasados e outros percalços que possam vir a ocorrer. Já no IHBDF isso não ocorreria, uma vez que a demanda seria programada em determinadas áreas, mas ocorrendo em paralelo com a demanda não programada dos serviços de emergência, que recebe um alto número de usuários diariamente, impossibilitando a continuidade no atendimento com a falta de recursos.

Por outro lado, assim como a Rede Sarah, o IHBDF seria gerido por um SSA, o que tornaria possível o recebimento de verbas por meio de emendas parlamentares e consequentemente um orçamento maior, isso não ocorre no HCB devido ao modelo de gestão adotado, que é por instituição de direito privado sem fins lucrativos e com a qualificação de OS, qualificação esta que impede o recebimento de dotações oriundas de emendas parlamentares.

Referências

1. Ministério da Administração Federal e da Reforma do Estado. Plano diretor da reforma do aparelho do Estado. Brasília, DF, 1995.

2. BRAVO, M. I. S. et al. Política de saúde na atual conjuntura: modelos de gestão e agenda para a saúde. Rio de Janeiro: UERJ, 2007.

3. Emenda Constitucional no 19, de 04 de junho de 1998. Modifica o regime e dispõe sobre princípios e normas da administração pública, servidores e agentes políticos, controle de despesas e finanças públicas e custeio de atividades a cargo do Distrito Federal, e dá outras providências.

4. FALCONER, A.P. A promessa do terceiro setor: um estudo sobre a construção do papel das organizações sem fins lucrativos e do seu campo de gestão. 1999. 150 f. Dissertação (mestrado em Administração) - Faculdade de Economia, Administração e Contabilidade, Universidade de São Paulo, São Paulo, 1999.

5. SZAZI, E. Terceiro setor: regulação no Brasil. 4.ed. São Paulo: Peirópolis, 2006. 439 p. 